\title{
Current Status of $H$. pylori Infection Treatment 2017
}

\author{
Bolai Paul $^{1 *}$, Senthil Adimoolam ${ }^{1}$, Mohd Javed Quereshi ${ }^{2}$ Jafrin Jahan Eva ${ }^{2}$ \\ ${ }^{1}$ Department of Dosage Form Design, Faculty of Pharmacy, MAHSA University, Selangor, Malaysia. \\ ${ }^{2}$ Department of Clinical Pharmacy, Faculty of Pharmacy, Universiti Teknologi Mara (UiTM), Selangor Darul Ehsan, Malaysia.
}

\begin{tabular}{l} 
ARTICLE INFO \\
\hline Article history: \\
Received on: 07/07/2017 \\
Accepted on: 19/09/2017 \\
Available online: $30 / 10 / 2017$ \\
\hline Key words: \\
Helicobacter pylori, Standard \\
regimen, Sequential regimen, \\
Quadruple regimen, \\
Concomitant regimen, \\
Levofloxacin regimen.
\end{tabular}

\begin{abstract}
H. pylori infection is highly associated with main symptoms and death that are recently affecting 50-75\% of the population in the world. But past few years' efforts, H. pylori treatment is more difficult and it is still standing challenges for medical practitioner due to antibiotic resistance and patient compliance, as there are no regimens can achieve the desired eradication rate. In fact, no new drug has been developed for $H$. pylori only using different mixtures of antibiotics and anti-secretory agents. Nowadays, antibiotics are frequently prescribed for this infection that is declining their effectiveness as a result of which growing antibiotic resistant worldwide. At present, standard therapy has been regarded as the first line treatment of $H$. pylori in many guidelines, but the eradication rate has decreased to unacceptable levels. Therefore, standard triple therapy is left due to increase in antibiotic resistance consequences low eradication rate. Alternative treatment regimens such as sequential, quadruple, concomitant, and levofloxacin therapies are most recommended eradicating $H$. pylori compare to triple therapy; one of them levofloxacin therapy is most excellent therapy for eradicating $H$. pylori infection in antibiotic resistant patients. Herein, this review discussed recent data focusing on diverse eradication regimens so as to emphasize the current $H$. pylori treatment and the significance of considering the occurrence of antibiotic resistance at a regional level when choosing a suitable therapy.
\end{abstract}

\section{INTRODUCTION}

H. pylori infection is a pathogenic bacterium which lives in the acidic condition of the gastrointestinal. Some researchers suggested that it is recognized as the most common chronic human bacterial infection (Zhao et al., 2014; Tan et al., 2011). It was the first exposed and acknowledged in 1982 by the Australian scientists Barry Marshall and Robin Warren (Nicholas Martinez et al., 2014).

One of the leading causes of infection around the world is due to the bacteria infection. H. pylori infection is nearly 50$75 \%$ affected of the worldwide demography, in the developing countries $70 \%$ of people are affected, whereas the percentages little lower, (25-50\%) in the developed countries (Safavi et al., 2016; Zhao et al., 2014). It is mainly attained earlier (about previously 10 years) and persist life. Most children are minor

\footnotetext{
* Corresponding Author

Email: bolai0199@gmail.com
}

extent affecting $H$. pylori from their mother, siblings, and fathers and also transmitted into the gastrointestinal tract to the oral cavity (e.g., Expression to vomit) and fecal to oral pathway from human beings to human beings. However, the incidence of this infection is not homogeneous international (Neil et al., 2014; Pacifico et al., 2010). The prevalence of $H$. Pylori infection is associated with lower social, financial situation, sanitation, basic hygiene, a poor diet, overcrowding, ethnicity, gender and age, low levels of education and geographic location which a major role in the distribution of infection (Sally et al., 2013; David et al., 2014).

The global occurrence of HP infection is related to more affect South America (30-90\%) such as Chile and Brazil than North America (30-90\%) as well as in Europe1.2-70\% (for example, in the Netherlands $1.2 \%$ ) is less than in the Middle East50-94\% (in most cases in Albania, Bulgaria, and Estonia). In contrast, the prevalence rate is lower in Australia (15-20\%) than in Africa (48-95\%) usually in Ethiopia and it is more prevalent in China up to 60 years old $(86 \%)$, as well as those vegetarian persons are amazingly more prevalent. 
The annual report that $H$. pylori re-infection rate is greater in Asia (4.3-13\%) than the west (0.5-2.5) (Ramesh et al., 2017). In Asia, studies shown that the prevalence of $H$. pylori infection rates are slightly higher more population country $(58 \%$ in China, $60 \%$ in South Korea, $75 \%$ in Vietnam, $79 \%$ in India, and $92 \%$ in Bangladesh) than lower population (31\% in Singapore, $36 \%$ in Malaysia, 39\% in Japan, $55 \%$ in Taiwan, $57 \%$ in Thailand)(Yang et al., 2014).

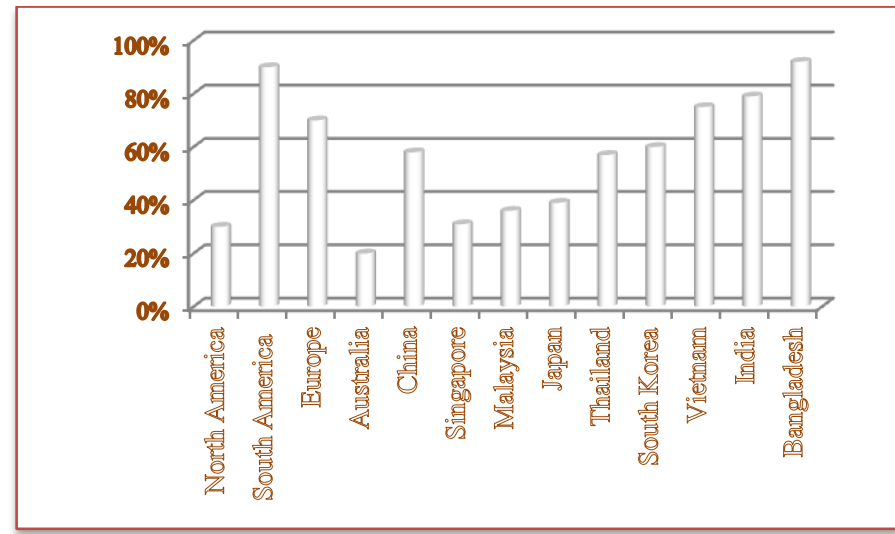

Fig. 1: Worldwide incidence rates for $H$. pylori infection.

H. pylori infection can lead to a different upper gastrointestinal disorder such as gastric inflammation (gastritis), heartburn, gastroesophageal reflux disease, gastric duodenal ulcer disease, gastric cancer and mucosa-associated lymphoid tissue (MALT). Up to 76-95\% of gastric cancers and $90 \%$ of duodenal ulcer is associated with H. pylori infection (Zhao et al., 2014; Ramesh et al., 2017;Sollano et al., 2015). Most infection, patients are asymptomatic and $10-15 \%$ patients infected on the increase chronic inflammation lead to atrophic gastritis, peptic ulcer in addition to gastric adenocarcinoma (Partha et al., 2016). There are different approaches for the eradication of infection caused by $H$. pylori. One of the widely used methods is several combined antibiotics, such as amoxicillin plus clarithromycin or metronidazole with a proton-pump inhibitor (Safavi et al., 2016).

At present, the eradication of $H$. pylori infection is main troubles antibiotic resistance, patients compliance and intolerance to therapeutic regimens (Niv et al., 2015). Antibiotic resistance is nowadays a major concern since one of the major causes of treatment failure against the $H$. pylori is drugs sensitive to this germ are getting resistant (De Francesco et al., 2010; Caliskan et al., 2015; Filipa et al., 2011). The causes of resistance are poor drug penetration, low drug concentration, short gastric residence time and antibiotic resistance represent a significant health care burden on society. Besides, the poor stability of antibiotics in gastric content requires frequent administration and leads to patient noncompliance (David et al., 2014). An ideal treatment of $H$. pylori infection has still to be found. At present, it is necessitated to develop making a new drug that is improving therapeutic efficacy (Hajiani et al., 2009; Michael et al., 2008).

The successful and complete eradication of $H$. pylori infection has become a challenging malignant disease worldwide
(Lu et al., 2014).There are different types of therapies using treatment of $H$. pylori infection such as standard, sequential, quadruple, concomitant and levofloxacin therapy. Those therapies are even the best for the treatment of this infection that is assure patient compliance to increase the high cure rate. But standard triple therapy has been recently declined efficacy due to antibiotic resistance resulting decreased eradication rates. Bismuth quadruple, concomitant, sequential and levofloxacin therapies are currently better than standard therapy that is providing promoted efficacy (Ermis et al., 2015; Papastergiou et al., 2014; Benjamin et al., 2010). Therefore, this study major purposed to provide a reconsideration modern beneficial efficacy of the drug and better eradication rates of $H$. pylori infection.

The recommended doses of standard, sequential, Quadruple bismuth, Concomitant and levofloxacin therapy drugs for treatment of $H$. pylori infection is shown in Table 1 .

Table 1: Current regimen for treatment of $H$. pylori infection.

\begin{tabular}{|c|c|}
\hline \multicolumn{2}{|r|}{ Standard regimen $(7-14 \mathrm{~d})$} \\
\hline 1. & $\begin{array}{l}\text { A PPI (standard dose, bid })+ \text { amoxicillin }(1 \mathrm{~g}, \text { bid })+ \\
\text { clarithromycin }(500 \mathrm{mg}, \text { bid }) \text {. }\end{array}$ \\
\hline 2. & $\begin{array}{l}\text { A PPI (standard dose, bid })+ \text { metronidazole }(400 \mathrm{mg}, \text { bid })+ \\
\text { clarithromycin }(500 \mathrm{mg}, \text { bid }) .\end{array}$ \\
\hline 3. & $\begin{array}{l}\text { A PPI (standard dose, bid })+ \text { amoxicillin }(1 \mathrm{~g}, \text { bid })+ \\
\text { metronidazole }(400 \mathrm{mg}, \text { bid }) \text {. }\end{array}$ \\
\hline 4. & $\begin{array}{l}\text { PPI (standard dose, bid })+ \text { amoxicillin }(1 \mathrm{~g}, \text { bid })+ \\
\text { furazolidone }(200 \mathrm{mg}, \text { bid }) .\end{array}$ \\
\hline \multicolumn{2}{|r|}{ Sequential regimen $(5 \mathrm{~d})$} \\
\hline 1 & APPI (standard dose, bid) + amoxicillin ( $1 \mathrm{~g}$, bid $)$. \\
\hline 2 & $\begin{array}{l}\text { A PPI (standard dose, bid })+ \text { amoxicillin }(1 \mathrm{~g}, \text { bid }) \text { followed } \\
\text { by PPI + clarithromycin }(500 \mathrm{mg})+\text { metronidazole }(500 \mathrm{mg}) \text {. }\end{array}$ \\
\hline 3 & $\begin{array}{l}\text { PPI (standard dose, bid) + amoxicillin }(1 \mathrm{~g}, \text { bid }) \text { followed by } \\
\text { PPI + clarithromycin }(500 \mathrm{mg})+\text { tinidazole }(500 \mathrm{mg}) .\end{array}$ \\
\hline \multicolumn{2}{|r|}{ Quadruple bismuth regimen $(7,10-14 \mathrm{~d})$} \\
\hline 1 & $\begin{array}{l}\text { A PPI (standard dose, bid })+ \text { bismuth }(240 \mathrm{mg}, \text { bid })+ \\
\text { amoxicillin }(1 \mathrm{~g}, \text { bid })+\text { furazolidone }(20 \mathrm{mg}, \text { bid }) .\end{array}$ \\
\hline 2 & $\begin{array}{l}\text { A PPI (standard dose, bid) + bismuth }(240 \mathrm{mg}, \text { bid })+ \\
\text { amoxicillin }(1 \mathrm{~g}, \text { bid })+\text { metronidazole }(400 \mathrm{mg}, \text { bid }) .\end{array}$ \\
\hline 3 & $\begin{array}{l}\text { A PPI (standard dose, bid) + bismuth }(240 \mathrm{mg}, \mathrm{qid})+ \\
\text { Tetracycline }(500 \mathrm{mg}, \mathrm{qid})+\text { Metronidazole }(500 \mathrm{mg} \text {, tid }) .\end{array}$ \\
\hline 4 & $\begin{array}{l}\text { A PPI (standard dose, bid) + bismuth subsalicylate }(525 \mathrm{mg} \text {, } \\
\text { qid) + metronidazole }(250 \mathrm{mg} \text {, qid })+\text { tetracycline }(500 \mathrm{mg} \text {, } \\
\text { qid). }\end{array}$ \\
\hline 5 & $\begin{array}{l}\text { Rabeprazole }(40 \mathrm{mg}, \text { bid })+\text { bismuth potassium citrate }(220 \\
\text { mg, bid })+ \text { metronidazole }(500 \mathrm{mg}, \text { tid })+\text { tetracycline }(500 \\
\mathrm{mg}, \mathrm{tid}) .\end{array}$ \\
\hline \multicolumn{2}{|r|}{ Concomitant regimen $(7-10 \mathrm{~d})$} \\
\hline 1 & $\begin{array}{l}\text { A PPI (standard dose, bid) + Clarithromycin }(500 \mathrm{mg}, \text { bid })+ \\
\text { Amoxicillin }(1 \mathrm{~g}, \text { bid })+\text { Metronidazole }(500 \mathrm{mg}, \text { bid }) \\
\text { +tinidazole }(500 \mathrm{mg}, \text { bid }) .\end{array}$ \\
\hline & Sitafloxacin therapy (7-d) \\
\hline 2 & $\begin{array}{l}\text { A PPI (standard dose, bid })+ \text { amoxicillin }(750 \mathrm{mg}, \text { bid })+ \\
\text { sitafloxacin }(100 \mathrm{mg}, \text { bid }) .\end{array}$ \\
\hline \multicolumn{2}{|r|}{ Levofloxacin regimen (5-7-d) } \\
\hline 1 & $\begin{array}{l}\text { A PPI (standard dose, bid }+ \text { levofloxacin }(500 \mathrm{mg} \text {, bid)+ } \\
\text { either amoxicillin }(1000 \mathrm{mg} \text { or tinidazole } 500 \mathrm{mg}, \mathrm{bid}) .\end{array}$ \\
\hline 2 & $\begin{array}{l}\text { Esomeprazole }(40 \mathrm{mg} \text {, bid + amoxicillin }(1 \mathrm{~g}, \text { bid }) \text { followed } \\
\text { by esomeprazole }(40 \mathrm{mg} \text {, bid })+\text { levofloxacin }(240 \mathrm{mg} \text {, bid }) \\
+ \text { metronidazole }(500 \mathrm{mg}, \text { bid }) .\end{array}$ \\
\hline 3 & $\begin{array}{l}\text { Esomeprazole }(20 \mathrm{mg}, \text { bid })+\text { amoxicillin }(1 \mathrm{~g}, \text { bid })+ \\
\text { levofloxacin }(250 \mathrm{mg}, \text { bid })\end{array}$ \\
\hline 4 & $\begin{array}{l}\text { Esomeprazole }(40 \mathrm{mg}, \text { bid })+\text { amoxicillin }(1000 \mathrm{mg} \text {, } \\
\text { bid)+levofloxacin }(500 \mathrm{mg}, \text { bid })\end{array}$ \\
\hline
\end{tabular}

Abbreviation: PPI: Proton pump inhibitor, bid: Twice daily, qid: Four times daily, tid: Three times daily, d: days. 


\section{First-line therapy}

Selection of drug for $H$. pylori infection regimens are influenced by diverse reasons involving efficacy, patient tolerance, existing antibiotic resistance, and worth of the drugs. Eradication rate should lead to $90 \%$ against $H$. pylori infection (Malekzadeh et al., 2004). Standard regimen such as clarithromycin plus proton pump inhibitor (PPI) plus amoxicillin or metronidazole for 7, 10 and 14 days is worldwide followed by first-line treatment regimen. It has revealed that PPI-based triple regimen which provided eradication rates greater than $80-90 \%$, usually consisting of a PPI, amoxicillin, and clarithromycin (Papastergiou et al., 2014). The recent national survey reported that the eradication rate of triple therapy, which is $84.92-87.50 \%$ from 2001 to 2007 , but $80-$ $81.43 \%$ from 2008 to 2010 (Sherief et al., 2016).Review studies have shown that eradication rate is highest using amoxicillin with PPI and clarithromycin $(83.50 \%)$ than metronidazole $68.64 \%$ as well as PPI, amoxicillin, and metronidazole the rate $82 \%$; each therapy lasting 14 days (Ermis et al., 2015).

The combination of antibiotics with PPI is still the best regimen in Hong Kong for 7 days administration and their eradication rate is $92.7 \%$ (Benjamin et al., 2010). Several studies have shown that In Europe, Canada is better efficacy (greater than $80 \%$ ) than Iranian (lower than $60 \%$ ), eradication rate is $76 \%$ for PPI, amoxicillin, and furazolidone in Iranian (Malekzadeh et al., 2004). In contrast, it found that the eradication rate is insufficiently less (lower than 45-60\%) in a few countries (Vaira et al., 2009). In Italian studies reported that triple therapies gain disappointing eradication rate, with a value lower than $80 \%$ and the standard 14days triple therapy cure rate is $70-81.70 \%$, whereas it seen that eradication rate is $74.80-82.22 \%$ obtained in different countries, such as Germany, Korea, and Latin America (De Francesco et al., 2016).

At present, reduction of the eradication rate with standard triple therapy due to antibiotic resistance which is reporting that lower than $80 \%$ (Yoon et al., 2016). The Amoxicillin resistance rate is $6.30-14.93 \%$ and clarithromycin rate is $23.70-71.20 \%$ during the period of 2003-2012. In recently proposed that the clarithromycin resistance rates in American, European, Turkey and South America populations are 29.3\%, 11.1\%, $47.5 \%$ and $17.2 \%$ and metronidazole resistance rates in Chinese population are75.6$95.4 \%$ whereas in Japan is $3.3-12.9 \%$. Recently viewed that amoxicillin resistance rate is comparatively declining almost 1-5\% in China and in more developed countries. Several studies have shown that antibiotic resistance and poor compliance due to treatment failure of this infection. As a result, first line therapy decrease eradication rates worldwide against $H$. pylori during the last few years (Kim et al., 2015, Chang et al., 2017, Zhang et al., 2015). Their cure rate is declining (50-60\%) for PPI, amoxicillin, and clarithromycin due to resistance to clarithromycin and metronidazole and their rate $38.5 \%$ in a turkey study (Dolapcioglu et al., 2014). In Japan, 7 days triple therapy cure rate is60-70\% due to widespread clarithromycin resistant (Hirata et al., 2016). Consequently, various ways have been recommended in order to avoid treatment failure of triple therapy, included in the treatment of duration, PPI effect on gastric acid secretion, other drug resistance and the patient's compliance. Esomeprazole is more anti-secretory effects of $H$. pylori eradication than other PPIs such as omeprazole, lansoprazole, and pantoprazole (Niv et al., 2015). Another currently approach to use sequential and quadruple bismuth therapy have better eradication rates for the H. pylori treatments compared to triple therapy (Doffou et al., 2015).

\section{Sequential therapy}

Sequential therapy is more effective in eradicating $H$. pylori infection instead of standard triple therapy and it is gaining a high eradication rate for administration either 7 or 10 day triple therapy. Sequential therapy actually second line treatment, for example, a proton pump inhibitor (PPI) plus amoxicillin $1 \mathrm{~g}$ according to a triple therapy, including a PPI with clarithromycin and tinidazoleis given for 5 days and their eradication rates are $91 \%$ and $93 \%$. On the contrary, changing the drug metronidazole used to give poor consequence compared to tinidazole and their eradication rate is $84 \%$ and $97 \%$. It has reported that the eradication rate of sequential therapy is more than $90 \%$ (Yoon et al., 2016; Vaira et al., 2009). In a recent, studies showed that eradication rate is higher for 5 days than 7- 10 days (De Francesco et al., 2014). Nowadays, it is developed to overcome standard therapy, antibiotic resistance against $H$. pylori their eradication rate is $63 \%$ and $71 \%$ for standard and sequential therapy (Dolapcioglu et al., 2014). Sequential therapy is fruitful in children and elderly patients (Lee et al., 2016).

But some studies reported that sequential and standard triple therapies are corresponding patient compliance and side effects. Patient compliance is little lower in sequential therapy $(92.6 \%)$ than standard therapy $(94 \%)$. On the other hand, side effects are more in sequential therapy (9.9) than standard therapy $(9.8 \%)$. Amoxicillin is more effective than other drugs due to low resistance rate and high $\mathrm{pH}$ environment. Some studies demonstrated that high-dose a PPI plus amoxicillin is overcoming resistance rate and their eradication rate is $72-81 \%$ (Safavi et al., 2016; Vaira et al., 2009). Recently, studies found that it is highly eradicating of $H$. pylori infection compared to first line therapy; after it cannot achieve in therapeutic efficacy treatment of this infection due to antibiotic bacterial resistance smoking and nonclear dyspepsia (Zullo et al., 2006).

\section{Quadruple bismuth therapy}

Bismuth-based quadruple therapy has been most excellent as regards the eradication rate because it is easily released into the gastric mucous layer with a low antibiotics resistance rate (Sarkeshikian et al., 2013;Jo et al., 2008). A quadruple therapy is consisting of bismuth, a PPI, and two antibiotics and their cure rate is $85-92 \%$ from Iranian to Netherlands (Malekzadeh et al., 2004). For example, combined with a PPI, bismuth subsalicylate, metronidazole and tetracycline for 10-14 days and their eradication rate is more than 95\% (Ermis et al., 2015). Other studies showed that eradication rate is $87-90 \%$ for PPI, bismuth, metronidazole, tetracycline (Nicholas et al., 
2014; Wong et al., 2016). In Turkey, studies reported that eradication rate is $94.2 \%$ for rabeprazole plus bismuth potassium citrate plus metronidazole plus and tetracycline given for 10 days, which recommended in the addition of bismuth can overcome difficult to clarithromycin resistant (Ayse et al., 2016).

Bismuth-based treatment may become sufficient until given with a PPI and cannot be recommended even because of long-term efficacy has not been found, but when furazolidone with bismuth is planned to combine for use in quadruple therapies resulting considerable side effects (Hajiani et al., 2009). Nevertheless, quadruple therapy is recently fall off treatment of $H$. pylori infection in nearly 20 to $30 \%$ patients due to two antibiotic resistance such as clarithromycin and metronidazole resistance (Gisbert et al., 2012). Recently found that quadruple therapy with PPI plus a single capsule containing three antibiotics (bismuth subcitrate, metronidazole, and tetracycline) is acquired a better eradication rate $(92-93 \%)$ and overwhelming metronidazole resistance (Manfredi et al.,2013).

\section{Concomitant therapy}

Concomitant therapy is an alternative treatment for standard triple therapy and it is the higher eradication rate $(90 \%)$ than standard triple therapy. In these therapies are providing three antibiotics with a PPI for 10 days such as esomeprazole plus amoxicillin plus clarithromycin and metronidazole have significantly superior eradication rates of $89 \%$ and $93 \%$. In a recent provide that dual drug resistance is $100 \%$ clarithromycin, $91 \%$ metronidazole and $25 \%$ clarithromycin, metronidazole $40 \%$, eradication rate are only $55 \%$ and $90 \%$ with concomitant therapy (Ramesh et al., 2017; Ermis et al., 2015). Different studies demonstrated that Concomitant therapy is the higher eradication administration for 5 days (De Francesco et al., 2014).Some studies have shown that the concomitant and sequential therapies are about same therapeutic effects and patient compliance, but patient compliance is little more than sequential (Lee et al., 2016). Several studies demonstrated that concomitant and sequential therapies are nearly uniform eradication rates and their eradication rates are 92.3\% and 93\% (Nicholas et al., 2014). On the other hand, concomitant therapy is more active and higher eradication rate about (90\%) than sequential therapy for antibiotic resistance patients, even high clarithromycin and metronidazole resistance (Julia et al., 2015).

\section{Levofloxacin therapy}

Levofloxacin is a broad-spectrum fluoroquinolone antimicrobial agent which inhibits the DNA synthesis and well tolerated (Cianci et al., 2006; Gisbert et al., 2006). Levofloxacin therapy is superior efficacy than triple therapy study in the US and it is the best treatment for $H$. pylori antibiotic resistance infected patients, especially metronidazole resistance $(76 \%)$ and clarithromycin resistance $(71 \%)$. In a recent study exposed that eradication rate is $90-92 \%$ for levofloxacin plus rabeprazole and either amoxicillin or tinidazole in a pilot study from Italy (Nicholas et al., 2014; Wong et al., 2006).

In other hands, it is used to fail standard triple and sequential therapy, and levofloxacin therapy is shown that eradication rate is more than $95 \%$ for esomeprazole plus amoxicillin followed by esomeprazole plus levofloxacin plus metronidazole for 5 days (Ramesh et al., 2017). It has been postulated that eradication rate $93-96 \%$ for esomeprazole, amoxicillin and levofloxacin administration of 7 days (Schrauwen et al., 2009). It is revealed that the cure rate is $90-92 \%$ for esomeprazole plus amoxicillin plus a levofloxacin administration for 10 days and their eradication rate is $87 \%, 91 \%$ and $96 \%$ study in Germany, Italian, and Netherlands (Skender et al., 2013). Choice of amoxicillin instead of metronidazole because the resistance rate of amoxicillin is minor than metronidazole; but the resistance rate is growing (9-13\%) in Korea (Moon et al.,2013).

Levofloxacin, esomeprazole and either amoxicillin or clarithromycin are highly effective and protective against $H$. pylori infection, but the combination with amoxicillin is better tolerated than the combination with clarithromycin. Levofloxacin therapy is fantastic bioavailability, higher eradication rate (more than 90\%) and low side effects (Schrauwen et al., 2009).Another same drug group is established that sitafloxacin based therapy is used to eradicate $H$. pylori infection in Japan instead of triple therapy and eradication rate is $70-80 \%$ for a PPI, amoxicillin, sitafloxacin (Hirata et al., 2016).

Table 2: Comparisons of the different methodsfor $H$. pylori infection treatment

\begin{tabular}{|c|c|c|c|c|c|}
\hline Variables & $\begin{array}{c}\text { Standard } \\
\text { therapy }\end{array}$ & Sequential therapy & Quadruple therapy & $\begin{array}{c}\text { Concomitant } \\
\text { therapy }\end{array}$ & Levofloxacin therapy \\
\hline Eradication rate & $80-90 \%$ & $63-90 \%$ & $89.95 \%$ & $89-93 \%$ & $90-96 \%$ \\
\hline Antibiotic resistance & More & Low & Lower than standard and sequential & More & Lower than other therapies \\
\hline Side effects & Low & More than standard therapy & Low & Low & Lower than other therapies \\
\hline Patients compliance & High & High & High & High & Higher than other therapies \\
\hline
\end{tabular}




\section{DISCUSSION}

A triple therapy is recommended first-line treatment of H. pylori infection (Zullo et al., 2010). In Asia and Africa, seven days administration with a PPI, amoxicillin or metronidazole and clarithromycin is the more effective eradication of $H$. pylori infection and their treatment regimens are well-tolerated and improve patient's compliance. At present, triple therapy is efficacy, low caused by antibiotics resistant, especially metronidazole and clarithromycin resistance. But it proved that non-metronidazole regimens are currently regarded and more suitable treatment of $H$. pylori infection in Asia and Africa. It is reported that eradication rate is $90 \%$ for clarithromycin, a PPI and amoxicillin for 7-10 days (Wong et al., 2000; Dolapcioglu et al., 2014). In the last decade, 7-10 days triple therapies have unacceptably low cure rates, but higher triple therapy has increased the cure rate as compared to 7-10 day regimen. When first-line therapy failed after a second-line levofloxacin therapy choose which is better efficacy administered for 14 days in the treatment of $H$. pylori infection (De Francesco et al., 2016). At present study, triple therapy failure of $H$. pylori eradication due to antibiotic resistance which resistance rate is more than $20 \%$ for clarithromycin, and $40 \%$ for metronidazole (Lee et al., 2016). So, alternative treatment is better than first line treatment such as sequential, concomitant Quadruple bismuth and Levofloxacin regimens (De Francesco et al., 2014).

Some studies have shown that sequential therapy is better efficacy for this infection, even there are main facts clarithromycin resistance as a result low eradication rate. Concomitant therapy is major problem dual antibiotic resistance (metronidazoleclarithromycin) after treatment failure, with metronidazole resistance rate is $60 \%$ in China-Iran-India, Central and South America (David et al., 2014).

In this regard, levofloxacin therapy is more effective for single or dual antibiotic resistance patients, especially clarithromycin and metronidazole, achieving cure rate is $90 \%$ (Federico et al., 2012). It is an appropriate therapeutic approach against $H$. pylori when sequential therapy failed (Zullo et al., 2006). Levofloxacin therapy cure rate is superior to quadruple therapy; it is shown that the eradication rate greater than $90 \%$ compared to quadruple therapy with a lower incidence of side effects (Wong et al., 2006; Ierardi et al., 2015).

\section{CONCLUSION}

Standard triple, sequential, quadruple bismuth and concomitant are the good therapeutic efficacy of $H$. pylori infection, but recently less effective due to antibiotic resistance and patient compliance. Levofloxacin therapy is a more effective treatment of this infection because low antibiotic rate and eradication rate is higher than other therapy especially metronidazole- clarithromycin resistance.

\section{Financial support and sponsorship: Nil.}

Conflict of Interests: There are no conflicts of interest.

\section{REFERENCES}

Ayse K, Sebahat B, Abdullah OY, Tarık TK, Muzaffer A, Ozlem T. Comparison of three different regimens against Helicobacter pylori as a first-line treatment: A randomized clinical trial. Bos J Basic Med Sci, 2016; 16(1):52-57.

Caliskan,Tokman, Erzin R, Saribas HB, Yuksel Y, Bolek S, Sevuk P. Demirci BK. Yilmazli EO, Akgul MO, Kalayci O, Cakan F, Salih H, Bal BK, Kocazeybek B. Antimicrobial resistance of Helicobacter pylori strains to five antibiotics, including levofloxacinin Northwestern turkey. Revistadasociedade Brasileirade Med Trop, 2015; 48 (3): 278-284.

Chang JY, Shim KN, Tae CH, Lee KE, Lee J, Lee KH, Chang MM, Kim SE, Jung Hk, Jung SA. Triple therapy versus sequential therapy for the first-line Helicobacter pylori eradication. BMC Gastroent, 2017; 17: 2-7.

Cianci R, Montalto M, Pandolfi F, Gasbarrini GB, Cammarota G. Third-line rescue therapy for Helicobacter pylori infection. W J Gastroent,2006; 12(15): 2313-2319.

David YG, Lee YC, Wu MS. Rational Helicobacter pylori Therapy: Evidence-Based Medicine Rather Than Medicine-Based Evidence. Cli GastroHep, 2014; 12:177-186.

De Francesco V, Giorgio F, Hassan C, Manes G, Vannella L, Panella C, Ierardi E, Zullo A. Worldwide $H$. pylori antibiotic resistance, a systematic review. J Gastro Liver, 2010; 19(4): 409-414.

De Francesco V, Hassan C, Ridola L, Giorgio F, Ierardi E, Zullo A. Sequential, concomitant and hybrid first-line therapies for Helicobacter pylori eradication: a prospective randomized study. J Med Mic, 2014; 63: 748-752.

De Francesco V, Ridola L, Hassan C, Bellesia A, Alvaro D, Vaira D, Zullo A. Two-week Triple Therapy with either Standard or High dose Esomeprazole for First-line H. pylori Eradication. J Gastro Liver Dis, 2016; 25(2): 147-150.

Dolapcioglu C, Aysun KY, Emel A, Aziz K, Dolapcioglu H, Aliye S, Resat D. Sequential therapy versus standard triple therapy in $H$. pylori eradication in a high clarithromycin resistance setting. Int J Cli Exp Med, 2014; 7(8): 2324-2328.

Doffou AS, Attia KA, Mamert FYB, Bangoura AD, KissyAnzouan YH, Kouamé HD, Mahassadi KA, Kouamé JN, Kouyaté M, Assi C, Dri-Yoman AHN. The H. pylori eradication rate in a high prevalence area (West Africa): Three triple therapy comparative studies. Open J Gastroent, 2015; 5: 200-206.

Benjamin CYW. Update on Management of Helicobacter Pylori Infection. Med bulletin, 2010; 15: 8-10.

Ermis F, Tasci ES. Current Helicobacter pylori treatment in 2014. W JMet, 2015; 5(2): 101-107.

Federico A, Nardone G, Gravina AG, Iovene MR, Miranda A, Debora CD, Pilloni PA, Rocco A, Ricciardiello L, Marmo R, Loguercio C, Romano M. Efficacy of 5-Day Levofloxacin-Containing Concomitant Therapy in Eradication of Helicobacter pylori Infection. Gastroent, 2012; 143: 55-61.

Filipa F, Monica V, Roxo R, Mónica O. Helicobacter pylori resistance to antibiotics science against microbial pathogens. Com Cur Res Tec Adv, 2011: 745-756.

Gisbert JP, Fernandez MC, Bermejo F, Angeles PA, Ducons J, Andez-Bermejo MF, Bory F, Cosme A, Benito LM, Laureano LR, Lamas E, Manuel P, David O, The H. pylori Study Group of the Association Espanolade Gastroenterological. Third-Line Rescue Therapy with Levofloxacin after Two $H$. pylori Treatment Failures. American J Gastroent, 2006; 101: 243-247.

Gisbert JP. Rescue Therapy for Helicobacter pylori Infection 2012. Gastroenterology Res and Pra, 2012: 2012: 1-12.

Hajiani E. Treatment for Helicobacter pylori infection, an overview.J Micro, 2009; 2(2): 41-46.

Hirata Y, Serizawa T, Satoki Shichijo S, Suzuk N, Sakitani K, Hayakawa Y, Yamada A, Koike K. Efficacy of triple therapy with esomeprazole, amoxicillin, and sitafloxacin as a third-line Helicobacter pylori eradication regimen. Int J Inf Dis, 2016; 51:66-69.

Ierardi E, Losurdo G, Giorgio F, Iannone A, Principi M, Di Leo A. Quinolone-based first, second and third-line therapies for Helicobacter 
pylori. W J Pharmaco, 2015; 4(4): 274-280.

Jo JH, Lee DH, Kang SJ. Comparison of the efficacy of Bismuth containing PPI-based quadruple therapy with PPI based triple therapy only as first-line Treatment for Helicobacter pylori Infection. Korean J Gastroint Endo, 2008; 37(4): 259-264.

Julia FMD, Alfred C, Gitu MD.Diagnosis and Treatment of Peptic Ulcer Disease and H. pylori Infection. American Fam Phys, 2015; 91 (4): 237-242.

Kim SE, Moo IP, Seun JP, Moon W, Choi YJ, Cheon JH, Kwon HJ, Ku KH, Yoo CH, Kim JH, Lee GW, Song SE. Trends in Helicobacter pylori eradication rates by first-line triple therapy and related factors in eradication therapy. Korean J Int Med, 2015; 30(6):801-807.

Lee JY, Kyung SP. Optimal First-Line Treatment for Helicobacter pylori Infection: Recent Strategies. Gastroenterology Res Pra, 2016; 2016: 1-7.

Lu B, Li M. Helicobacter pylori eradication for preventing gastric cancer. WJ Gastroent, 2014; 20(19): 5660-5665.

Malekzadeh R, Mohamadnejad M, Siavoshi F, Massarrat S. Treatment of Helicobacter pylori infection in iran: low efficacy of recommended western regimens. Arch Iranian Med, 2004; 7(1): 1 - 8 .

Manfredi M, Barbara B, Elisabetta M, Alessandro F, Pierpacifico G, Angelis GLD.Which Treatment in Helicobacter pylori Infection?. Clin Exp Pharmacol, 2013; 3(4): 2-3.

Michael S, Peter M. New strategies for Helicobacter pylori eradication. CurOpiPharmacol, 2008; 8:593-597.

Moon JY, Kim GH, You HS, Lee BE, Ryu DY, Cheong JH, Jung JI, Jeong JH, Song CS, Song GA. Levofloxacin, Metronidazole, and Lansoprazole Triple Therapy Compared to Quadruple Therapy as a Second-Line Treatment of Helicobacter pylori. Inf Korea. Gut and Liver, 2013; 7 (4): 406-410.

Neil H. Stollman, David Y. Graham. Rallying community health care providers to close the gap between $H$. Pylori guidelines and the challenges of eradication. Gastroente Hep, 2014; 10(12): 811-814.

Nicholas Martinez MD, KarthikGarapati MD, Charles Randall MD. Management of Helicobacter Pylori Infection. J Tro Dis, 2014; 2(1):1-3.

Niv Y, Rokkas T. Recent advances in Helicobacter pylori eradication. Annals of Gastroenterology,2 015; 28:415-416.

Pacifico L, Anania C, John FO, Ferraro F, Chiesa C. Consequences of Helicobacter pylori infection in children. W J Gastroent, 2010; 16(41): 5181-5194.

Partha P. Current status of Helicobacter pylori associated human gastric cancer and the therapeutic approaches - A Review. World sci News, 2016; 52: 162-180.

Papastergiou V, Georgopoulos SD, Karatapanis S. Treatment of Helicobacter pylori infection: Past, present and future. W J Gas Pathophy, 2014; 5(4): 392-399.

Ramesh R, Sheng LW, Jing Li, Ying XW, Qian WR, Chang QY. Helicobacter pylori infection: A recent approach to diagnosis and management. J Biomed, 2017; 2(1): 45-56.

Safavi M, Sabourian R, Foroumadi A. Treatment of Helicobacter pylori infection: Current and future insights. W J Cli Cases, 2016; 4(1): 5-19.

Sally C, Hsiu-Ju C, Rachel M, Karen J. Goodman and the Can Help Working Group. Helicobacter pylori incidence and re-infection in the Aklavik H. pylori Project. Int J Circumpolar Health, 2013; 72: 1-7.

Sarkeshikian SS, Iranikhah A, Ghadir MR. Azithromycin based triple therapy versus standard clarithromycin based triple therapy in eradication of Helicobacter pylori infection in Iran: a randomized controlled clinical trial. Turkish J Gastroent, 2013; 24 (1): 10-14
Schrauwen RWM, Janssen MJR, De Boer WA. Seven-day PPItriple therapy with levofloxacin is very effective for Helicobacter pylori eradication. J Med, 2009; 67(3): 96-101.

Sherief AE, Saly EN, Walaa E, Shereen A, Loai M, Lobna Abo A, Samah S. Increasing rates of treatment failures with the standard triple therapy for Helicobacter pylori: a unique and alternative treatment option is urgent. Indian J Med Res Pharm Sci, 2016; 3(4): 13-16.

Skender T, Suzana MK, Bledar K, Gentiana Q, Skerdi P, Hajrullah F. The Efficacy of Levofloxacin-based Triple Therapy for Firstline Helicobacter Pylori Eradication. Medical Archives, 2013; 67(5): 348350 .

Sollano JD, Lunas KE, Marotta F. Decreasing Incidence of Gastric Cancer and H. pylori Infection a 10-Year Study from an Asian Population. CliPharmacoBiopharm, 2015; 4(4): 1-2.

Tan V, Wong B. Helicobacter pylori and gastritis: untangling a complex relationship 27 years on. J Gastroent Hepato, 2011; 26:42-45.

Vaira D, Zullo A, Hassan C, Fiorini G, Vakil N. Sequential therapy for Helicobacter pylori eradication: the time is now!. Therapeutic Advances in Gastroenterology, 2009; 2(6): 317-322.

Wong U, McLean LP. Diagnosis and Management of Helicobacter pylori. J Cli Gastroent Tre, 2016; 2: 1-6.

Wong WM, GU Q, Chu KM, Yee YK, Fung FMY, Tong TSM, Chan AOO, Lai KC, Chan CK, Wong BCY. Lansoprazole, levofloxacin and amoxicillin triple therapy vs. quadruple therapy as second-line treatment of resistant Helicobacter pylori infection. Alimen Pharmaco The, 2006; 23: 421-427.

Wong BCY, Chang FY, Abid S, Abbas Z, Lin BR, Rensburg CV, Chen PC, Schneider H, Simjeei AE, Hamid SS , Seebaran A, Zhang J, Destefano M, Lam SK. Triple therapy with clarithromycin, omeprazole, and amoxicillin for eradication of Helicobacter pylori in duodenal ulcer patients in Asia and Africa. Alim Pharmaco The, 2000; 14: 1529-1535.

Yang JC, Lu CW, Lin CJ. Treatment of Helicobacter pylori infection: Current status and future concepts. W J Gastroent, 2014; 20(18): 5283-5293.

Yoon H, Lee DH, Jang ES, Kim J, Shin CM, Park YS, Hwang JH, Kim JW, Jeong SH, Kim N. Effects of N-acetylcysteine on First-Line Sequential Therapy for Helicobacter pylori Infection: A Randomized Controlled Pilot Trial. Gut and Liver, 2016;10 (4): 520-525.

Zhao S, Yan Lv, Jian-Bin Z, Wang B, Guo-Jun Lv, Xiao-Jun Ma. Gastroretentive drug delivery systems for the treatment of Helicobacter pylori. W J Gastroent,2014; 20(28): 9321-9329.

Zhang M. High antibiotic resistance rate: A difficult issue for Helicobacter pylori eradication treatment.WJGastroente,2015; 21(48): 13432-13437.

Zullo A, De Francesco V, Manes G, Scaccianoce G, Francesca Cristofari F, Hassan C. Second-line and Rescue Therapies for Helicobacter pylori Eradication in Clinical Practice. J Gastro Liver Dis, 2010; 19 (2): 131-134.

Zullo A, De Francesco V, Hassan C, Panella C, Morini S, Ierardi E. Second-line treatment for Helicobacter pylori eradication after sequential therapy failure: a pilot study. Therapy, 2006; 3(2): 251-254.

\section{How to cite this article:}

Paul B, Adimoolam S, Quereshi MJ, Eva JJ. Current Status of $H$. pylori Infection Treatment 2017. J App Pharm Sci, 2017; 7 (10): 190-195. 